\title{
Akt-1/2 Inhibitor-treated Tumor Infiltrating Lymphocytes
}

National Cancer Institute

\section{Source}

National Cancer Institute. Akt-1/2 Inhibitor-treated Tumor Infiltrating Lymphocytes. NCI

Thesaurus. Code C123720.

Autologous tumor infiltrating lymphocytes (TILS) harvested directly from the infiltrate of a patient's tumor and treated with an inhibitor of the serine/threonine kinases Akt-1 and 2 (Akti-1/2) during ex vivo expansion, with potential antineoplastic activity. Upon reintroduction into the patient, the Akti-1/2-treated TILs recognize and kill cancer cells. Akt inhibition promotes the immunologic memory of the TILs and enhances their expansion, in vivo long-term persistence and antitumor activity. 